\title{
Mesoporous silicalite- 1 nanospheres and their properties of adsorption and hydrophobicity
}

\author{
Qin Hu, Bao Juan Dou, Hua Tian, Jin Jun Li, Peng Li, Zheng Ping Hao* \\ Department of Environmental Nano-Materials, Research Center for Eco-Environmental Sciences, Chinese Academy of Sciences, Beijing 100085, PR China
}

\section{A R T I C L E I N F O}

\section{Article history:}

Received 26 March 2009

Received in revised form 29 June 2009

Accepted 31 August 2009

Available online 3 September 2009

\section{Keywords:}

Mesoporous silicalite-1 nanospheres

Hydrophobicity

Adsorption

VOCs

\begin{abstract}
A B S T R A C T
The mesoporous silicalite-1 nanospheres (MSNs) had been successfully synthesized by using silicalite-1 seeds as silica source, cetyltrimethylammonium bromide (CTAB) as the surfactant and diethyl ether as the cosolvent via a novel and facile approach, which had a structure analogous to HMS materials, but contained sillicalite-1 zeolite as the mesoporous wall. A variety of experimental techniques of transmission electron microscopy (TEM), scanning electron microscopy (SEM), X-ray diffraction (XRD) and $\mathrm{N}_{2}$ adsorption/desorption isotherms had been used to characterize the framework structure, porosity and morphology of this novel mesoporous silicalite- 1 nanospheres. The obtained nanospheres had the diameters of $300-500 \mathrm{~nm}$ and possessed worm-like porous walls. The MSNs materials exhibited high surface areas and large total pore volumes, and the order of the mesoporous structures increased with the amount of the added cosolvent. Due to the complementary types of porous structures, MSNs materials were used to conduct the adsorption experiments under static and dynamic conditions. The equilibrium adsorptive experiments of toluene for MSNs samples presented a high adsorption capacity compared to the results reported by the other literatures. And the hydrophobicity index (HI) estimated by the dynamic adsorption process under wet conditions indicated that the MSNs materials possessed high dynamic adsorptive capacities and super-hydrophobic properties.
\end{abstract}

(c) 2009 Elsevier Inc. All rights reserved.

\section{Introduction}

Emissions of volatile organic compounds (VOCs), which would result in harmfully healthy and seriously environmental problems, are becoming one of the most stringent environmental challenges in many industrial processes. There are a number of technologies available for VOCs abatement, among which, sorption is a reliable chemical engineering method widely used because of the flexibility of the system, low energy and cheap operation costs. The MFI type silicalite-1 (Sil-1) zeolite without cations and silanols defects exhibits high hydrophobic property during the adsorption of volatile organic compounds (VOCs) under wet conditions [1-3]. However, the microporous nature of Sil-1 zeolite (diameter $<2 \mathrm{~nm}$ ) disables the bulky molecules access to the inner pores due to the mass diffusion [4]. Although mesoporous materials with the amorphous walls have large pore diameter to overcome the diffusion limitation of mass transfer during the adsorption process, they exhibit hydrophilic and low thermal/hydrothermal stability compared to zeolitic materials (such as Sil-1 zeolite) [5,6]. In order to overcome these problems, the hybrid materials aim to address this field [7], which both contain zeolites and controlled mesoporosity.

\footnotetext{
* Corresponding author. Tel.: +8610 62923564/62849194; fax: +861062923564.

E-mail address: zpinghao@rcees.ac.cn (Z.P. Hao).
}

The introduction of mesopores into zeolites has recently been achieved using several strategies to generate mesostructured zeolitic materials [8-10]. Thus, the mesoporous silicalite- 1 materials have been designed and synthesized, especially used in the adsorption process under humid environments due to the hydrophobicity of the pore wall formed by the Sil- 1 zeolites. However, it remains a challenge that the majority of ordered mesoporous materials cannot be synthesized in crystalline form under various synthesis conditions.

Recently, more efforts have been focused on porous capsules and spheres of well-defined structure morphologies due to their large total pore volume and surface area, high permeability, and potential applications as adsorbents [3,11], catalysts [12-14], drug controlled release carriers [15-19] and so on. These studies concentrated mainly on the porous structure, morphology and application. Chen et al. [15] reported the synthesis of porous silica nanocapsules and silica nanospheres by a novel combination of stabilizing condensation and dynamic self-assembly, and taking ethyl ether and 2-ethoxyethanol as cosolvents, respectively. The final products exhibited high BET specific surface areas and large pore volumes. Zhang et al. [20] successfully synthesized organosiliceous multilamellar vesicles (MLVs) with tunable number of layers and sponge-like walls via one surfactant templating, the specific surface area and pore volume of which are as large as 
$695 \mathrm{~m}^{2} / \mathrm{g}$ and $2.10 \mathrm{~cm}^{3} / \mathrm{g}$, respectively. Therefore, it is significant to attempt to synthesize mesoporous silicalite- 1 nanospheres, and the new materials may be useful for applications in the adsorption of VOCs under wet conditions.

Ordered mesoporous aluminosilicates with completely crystalline zeolite wall structure have gathered considerable research interest as solid catalysts and adsorbents [21], especially in the bulk molecules of large size involved process [22]. Much attention has been focused on the nanocasting method using various forms of carbon (CMKs) as template to replicate mesopore-containing zeolites [10,22-25]. However, attempts to synthesize mesoporous zeolites by using CMKs as hard template easily obtained an agglomerate of nanocrystals with disordered mesoporous structure. Other approach was developed to transform the amorphous pore walls of ordered mesoporous silicate into crystalline zeolite by Campos et al. [26] that recrystallized mesoporous SBA-15 into microporous ZSM-5 under autogenous pressure in glycerol containing different amounts of water. Navascués et al. [3] synthesized hollow silicalite-1 spheres (HSSs) produced by liquid phase hydrothermal from mesoporous silica spheres (MSSs) seeded with silicalite-1 nanocrystals. However, only low total pore volume and surface area (ca. $0.3 \mathrm{~cm}^{3} / \mathrm{g}$ and $400 \mathrm{~m}^{2} / \mathrm{g}$, respectively) were obtained, which would limit the dynamic adsorption capacity of VOCs according to the Kosuge et al.'s observation [27]. Hereby, to increase the total pore volume and surface area of the mesostructured zeolitic materials remains a challenge.

In this work, with the purpose to synthesize mesoporous silicalite-1 materials with high pore volume and surface areas, superhydrophobic property, fast diffusion and good accessibility, we present a novel and facile method to synthesize mesoporous silicalite- 1 materials by using silicalite- 1 seeds as silica source, cetyltrimethyl-ammonium bromide (CTAB) as the surfactant and diethyl ether as the cosolvent. And we also explored their application possibility for the adsorption of VOCs under static and dynamic conditions. To our best knowledge, no reports have ever been released on such an approach to the preparation of mesoporous silicalite- 1 nanospheres by a direct synthesis process.

\section{Experimental}

\subsection{Chemicals}

Tetrapropylammonium hydroxide solution (TPAOH) (20\%), silica sol (25\%), ammonia solution (25-28\%), and diethyl ether $(\geqslant 99.5 \%)$ were purchased from Beijing Chemical Reagent Co. Cetyltrimethylammonium bromide (CTAB) $(\geqslant 99 \%)$ was obtained from Tianjin Chemical Reagent Co. All chemicals were analytic grade and were used as received without further purification.

\subsection{Synthesis of mesoporous silicalite-1 nanospheres}

The mesoporous silicalite-1 nanospheres (MSNs) were synthesized under alkalescent condition by using silicalite- 1 seeds as silica source, CTAB as the surfactant and diethyl ether as the cosolvent. In a typical synthesis, silicalite- 1 seeds were prepared as a similar method described by Lechert and Kleinwort [28]. Firstly, homogenous solution with the molar composition of 1 TPAOH: $3.0 \mathrm{NaOH}$ : 87.2 Silica Sol: $152.5 \mathrm{H}_{2} \mathrm{O}$ was aged for $16 \mathrm{~h}$ at $100{ }^{\circ} \mathrm{C}$. Secondly, $1 \mathrm{~g}$ of CTAB was dissolved in $140 \mathrm{~mL}$ of $\mathrm{H}_{2} \mathrm{O}$, and thirdly $1 \mathrm{~mL}$ of ammonia solution (25-28\%) and a certain amount $(20,40,60,100$ and $120 \mathrm{~mL})$ of diethyl ether were added into. With the mixture vigorously shaken in a conical flask at room temperature for $1 \mathrm{~h}, 10 \mathrm{~g}$ of the prepared solution containing silicalite- 1 seeds were dripped into, and the mixture was shaken for $24 \mathrm{~h}$. Subsequently, the mixture was heated at $50{ }^{\circ} \mathrm{C}$ for driving the diethyl ether away, and then the mixture was crystallized in Teflon bottles at $175^{\circ} \mathrm{C}$ for $8 \mathrm{~h}$. In the following steps, all the crystallized products were filtered, washed with pure water, dried at $100{ }^{\circ} \mathrm{C}$ and calcined at $600{ }^{\circ} \mathrm{C}$ for $4 \mathrm{~h}$ with the heating rate of $10^{\circ} \mathrm{C} / \mathrm{min}$. The prepared white powers of mesoporous silicalite- 1 nanospheres were named as MSN- $x$ ( $x$ is the amount of diethyl ether, $20,40,60,100$, and 120 , respectively).

\subsection{Characterizations}

Low angle X-ray diffraction (XRD) patterns and high angle XRD patterns were measured on TTR-III diffractometer with $\mathrm{Cu}-\mathrm{K} \alpha$ radiation $(\lambda=0.1542 \mathrm{~nm})$ at a voltage of $40 \mathrm{kV}$ and a current of $40 \mathrm{~mA}$ in the range of $0.7-7.0^{\circ}$ and $5-35^{\circ}$, respectively. Nitrogen adsorption/desorption were measured at liquid nitrogen temperature $\left(-196^{\circ} \mathrm{C}\right)$, using a NOVA 1200 gas sorption analyzer. Before the measurements, the samples were degassed under vacuum condition at $300{ }^{\circ} \mathrm{C}$ for $3 \mathrm{~h}$. The Brunaur-Emmett-Teller (BET) surface areas were calculated based on the linear part of the BET plot $\left(P / P_{0}=0.05-0.25\right)$. The total pore volumes were estimated according to nitrogen uptake at a relative pressure $\left(P / P_{0}\right)$ of ca. 0.99 . The pore size distribution was derived from the desorption branch of $\mathrm{N}_{2}$ isotherms using Barrett-Joyner-Halenda (BJH) method [29]. Transmission electron microscopy (TEM) images were collected on a Hitachi H-7500 operating at an accelerating voltage of $120 \mathrm{kV}$. Scanning electron microscopy (SEM) observations measurements were carried out on a Hitachi S-3000 N instrument operating at $20 \mathrm{kV}$. Infrared spectra were recorded on a Braker Tensor 27 using diffuse reflectance infrared Fourier transform spectroscopy (DRIFT) techniques.

\subsection{Adsorption apparatus}

The Intelligent Gravimetric Analyzer (IGA-002, Hiden) was used to measure the adsorption isotherms of toluene for the sample MSN- $x$ by using the gravimetric method. The sample weighed about $50 \mathrm{mg}$ for each run. Before the measurements, the sample in the vessel of IGA-002 was vacuumed up to $10^{-5}$ millibar and outgassed at $100^{\circ} \mathrm{C}$ for $24 \mathrm{~h}$. And the adsorption experiments were carried out at various temperatures of $25^{\circ} \mathrm{C}, 35^{\circ} \mathrm{C}$ and $45^{\circ} \mathrm{C}$.

The dynamic adsorption experiments of VOCs were conducted in a fixed bed column at a constant temperature $\left(20^{\circ} \mathrm{C}\right)$, in which adsorbents are packed. And the experimental setup is represented schematically in our previous study [30]. The samples were crushed and sieved between 40 mesh and 60 mesh, and about $100 \mathrm{mg}$ of pelletized sample was loaded in the adsorption bed. Before the adsorptive process, the samples were heated at $120^{\circ} \mathrm{C}$ for $24 \mathrm{~h}$ under vacuum condition to remove the physical adsorption of water molecules and other organic impurities adsorbed in pores. To study the hydrophobicity of MSN- $x$ adsorbents, a mixture of VOC stream and nitrogen gas carrier under different relative humidities stimulated was estimated to study the efficiency of the adsorbents. In our study, the total gas flow rate is $100 \mathrm{~mL} /$ min and the VOCs (such as benzene) concentration is ca. $800 \mathrm{ppm}$ under both dry (without water vapors) and wet conditions.

\section{Results and discussion}

\subsection{Characterizations of mesoporous silicalite-1 nanospheres}

The mesoporous silicalite- 1 nanospheres were synthesized by using silicalite- 1 seeds as silica source, CTAB as the surfactant and diethyl ether as the cosolvent. TEM, XRD and $\mathrm{N}_{2}$ adsorption/ desorption isotherms techniques were used to characterize the MSN- $x$ materials. 
The TEM images of samples MSN-0, MSN-40 and MSN-100 were illustrated in Fig. 1. All three samples showed a spherical morphology with diameters of $300-500 \mathrm{~nm}$. At higher magnifications (Fig. 1), it could be seen that the nanospheres exhibited shortrange ordered mesoscopic pore structures, which had a mesoporous structure analogous to HMS materials. Apparently, worm-like pores ca. $3 \mathrm{~nm}$ in width were present inside the nanospheres, which indicated that the MSNs can be synthesized by using silicalite- 1 seeds as silica source, CTAB as the surfactant and diethyl ether as the cosolvent via a facile approach. Fig. 2 shows typical SEM images of the morphology of MSN-60 and MSN-100 samples. As shown in Fig. 2, the diameters of these nanospheres were covering a wide range of $200-600 \mathrm{~nm}$. However, the diameters of the most of the nanospheres were between 300 and $500 \mathrm{~nm}$, which is corresponding to the TEM results.

To investigate the effect of the amount of cosolvent added in the initial synthesis on the formation of silica nanospheres, a series of comparative experiments were carried out. As illustrated in Figs. 1 and 2, with the increase of the amount of the cosolvent, the average diameter of the nanospheres increases significantly, which indicated that the cosolvent acted as the template to some extent in the original synthesis. And as the increase of the amount of cosolvent, the mesoporous structures became more ordered, which would be further investigated by the X-ray diffraction patterns in Fig. 3(a) and (b). However, compared with those samples, the particle size, mesoporous diameter and morphology of the silica nanospheres did not change much. Though TEM and SEM images of MSN- $x$ materials demonstrated morphology and the pore
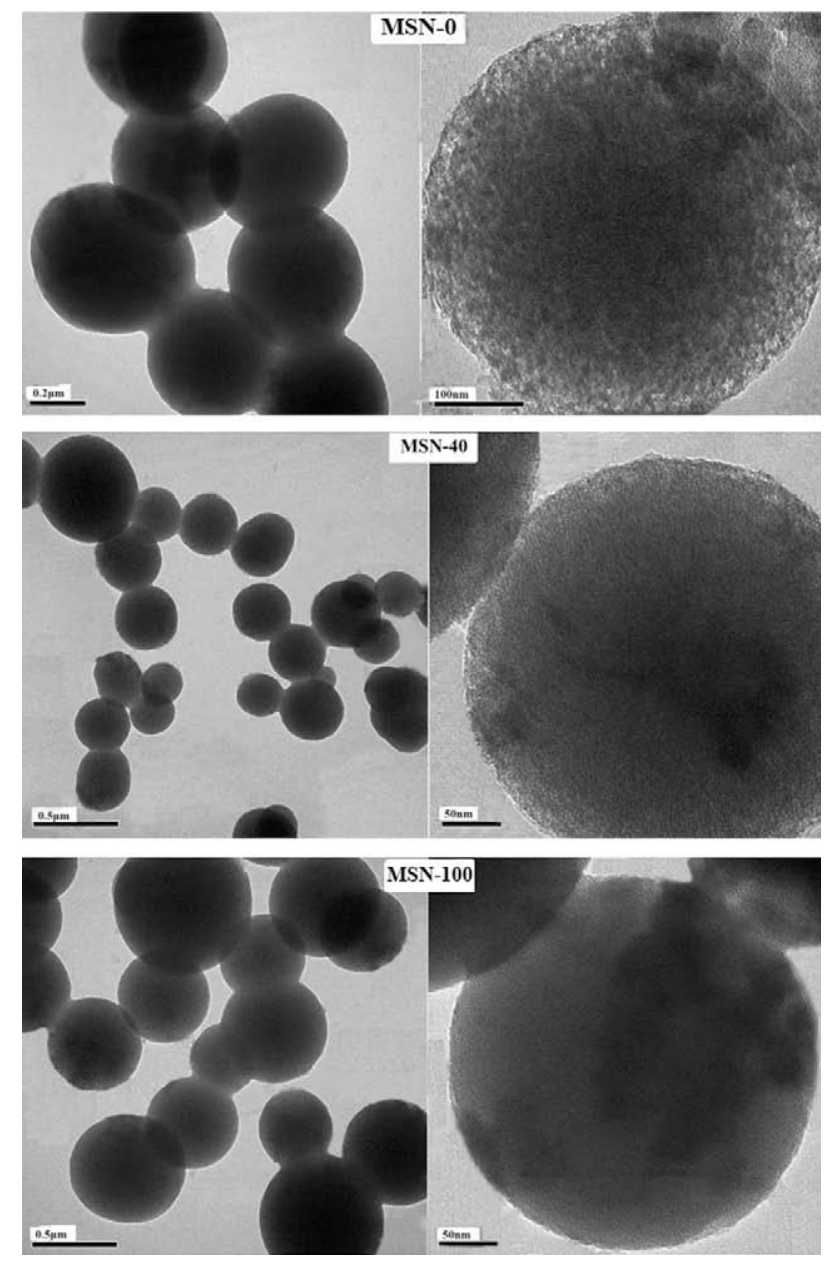

Fig. 1. TEM images at low and high magnifications of nanospheres of MSN-0, MSN40 and MSN-100 samples. structures of the nanospheres, it necessitated further comprehensive investigation to confirm the crystallization of the pore wall and the ordered mesoporous structures.

The low angle X-ray diffraction patterns and high angle X-ray diffraction patterns for MSN- $x$ materials were shown in Fig. 3(a) and (b), respectively. For the MSN-0 sample, the low angle XRD revealed a peak at ca. $2.1^{\circ}(2 \theta)$ and two broad peaks between $3^{\circ}$ and $5^{\circ}(2 \theta)$ in Fig. 3(a), which corresponded to HMS mesoporous phase with wormhole-like mesostructure [31,32]. These low angle peaks disappeared for the MSN-20 sample when certain amount of cosolvent added during the synthesis procedure. However, with the increase of the added cosolvent amount in the initial synthesis mixtures, the broad peak at ca. $2 \cdot 1^{\circ}(2 \theta)$ appeared again and the intensity of the peak for the MSN- $x$ samples increased. These results implied that more ordered porous structures of MSN materials had been produced by increasing the amount of the cosolvent, which was consistent with Chen et al.'s observation [15]. However, too much amount of the added cosolvent would disorder the mesostructure, as the peak disappeared again for MSN-120 sample shown in Fig. 3(a). The high angle XRD data in Fig. 3(b) exhibited distinctive peaks of crystalline silicalite- 1 zeolite structure at $7.8^{\circ}, 8.8^{\circ}, 23^{\circ}, 23.6^{\circ}$ and $24.4^{\circ}(2 \theta)$ for all MSN- $x$ samples, which can be indexed as (101), (200), (501), (303) and (133) reflections $[1,3]$, respectively. Compared to Sil-1 zeolite, the intensities of the related peaks of MSN- $x$ materials were much lower, which indicated that the synthesis method had some inverse influence on the formation of crystalline zeolite pore wall. However, it would be of great interest that the MSN- $x$ materials with crystalline zeolite pore wall structure contained both mesopores and micropores had been successfully synthesized, which is also validated by the TEM results above.

Fig. 4 displayed typical nitrogen adsorption-desorption isotherms (a) and BJH pore size distribution (b) of MSN- $x$ patterns. All the isotherms exhibited three sharp increases at the relative pressures of $P / P_{0}<0.05,0.3<P / P_{0}<0.5$ and $P / P_{0}>0.8$. At low relative pressure part of $P / P_{0}<0.05$, a steep rise followed by a relatively flat curve contributed to micropore filling [5,33]. All adsorption/ desorption curves showed typical type-IV isotherms at the relative pressures of $0.3<P / P_{0}<0.5$ with type $\mathrm{H} 1$ hysteresis loops in accordance to IUPAC nomenclature classification [34] and a broad hysteresis loop at $P / P_{0}>0.8$, which belonged to the presence of mesoporous channels and interparticle voids $[10,35]$, respectively. In addition, the three types of porous structures were also validated from the hierarchical BJH pore size distribution shown in Fig. 4(b), which revealed that the mesoporous silicalite-1 nanospheres possessed tri-modal of pores including micropores, mesopores and stacking voids pores. On the other hand, the exist of tri-modal pores also indicated that the MSN- $x$ materials contained crystalline Sil-1 zeolites pore wall structure, which micropores produced.

Table 1 shows the porous characteristics of the mesoporous silicalite-1 nanospheres and Sil-1 zeolites. Compared to Sil-1 zeolites, MSN- $x$ patterns exhibited much higher BET surface areas and larger total pore volumes, which promised higher adsorptive capacity of volatile organic compounds. Moreover, the total pore volumes of the products MSN- $x$ patterns increased as the cosolvent added in during the synthesis process, as the total pore volume changed from $0.823 \mathrm{~cm}^{3} / \mathrm{g}$ for MSN-0 sample to $1.206 \mathrm{~cm}^{3} / \mathrm{g}$ for MSN-60 sample, which was similar to Chen et al.'s results [15]. However, the relationship between the amount of the cosolvent and the total pore volume of the MSN- $x$ materials was nonlinear. As the cosolvent evaporated out of the vessel before crystallization, it had a weak influence to the mesoporous size distribution of $\mathrm{MSN}-x$ materials shown in Table 1. Obviously, the MSN- $x$ materials had a wider size distribution that approved a high affinity for various VOCs due to their complementary types of porous structures [30]. 

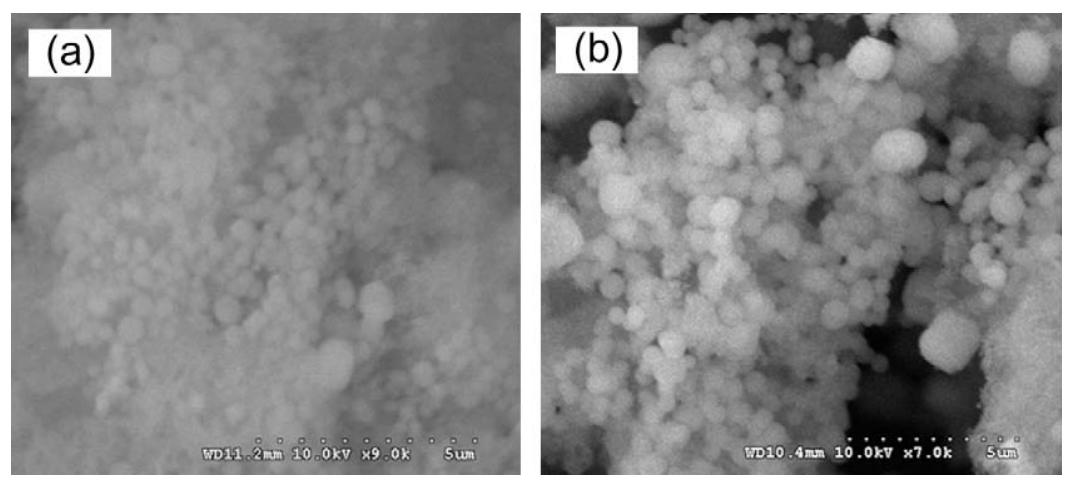

Fig. 2. SEM images of MSN-60 (a) and MSN-100 (b) samples.
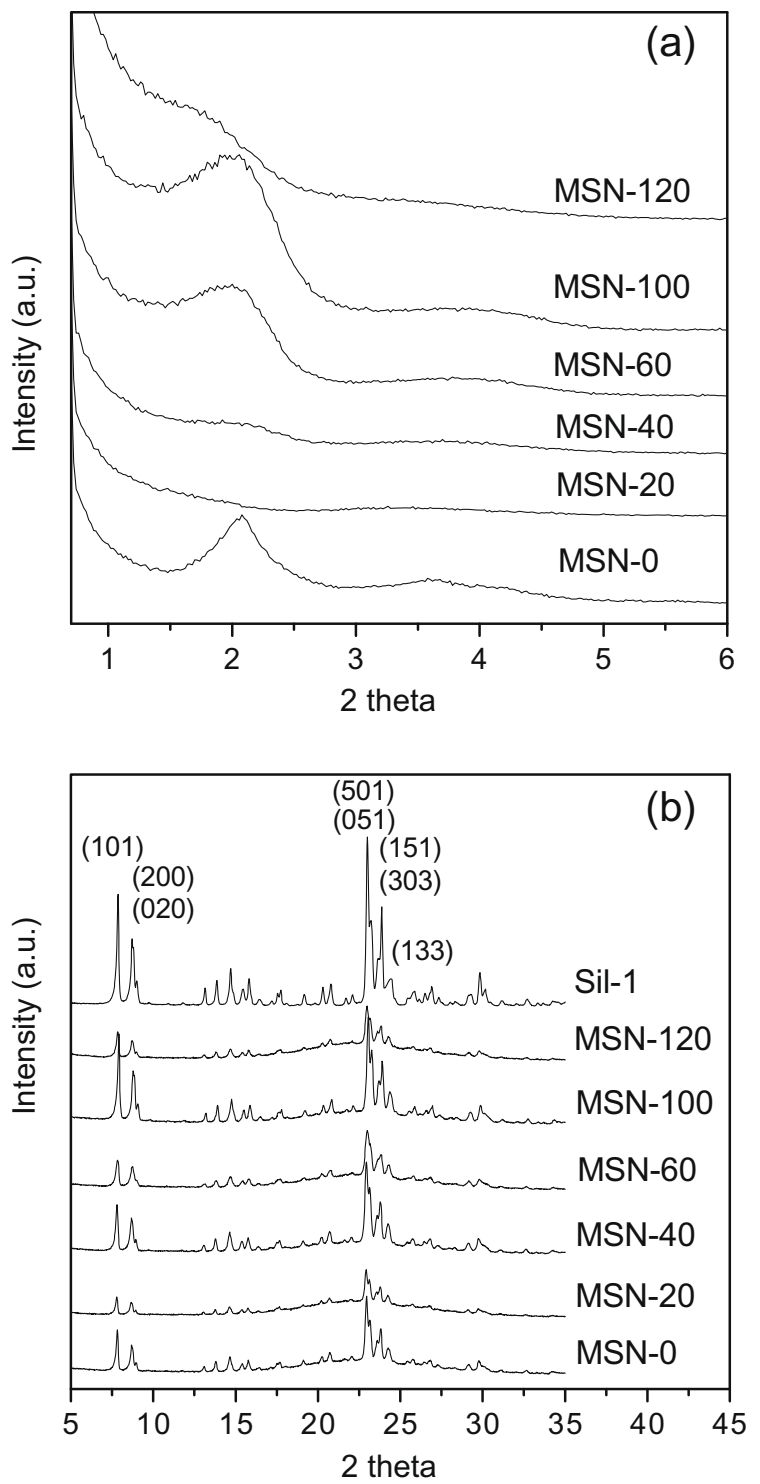

Fig. 3. Low angle X-ray diffraction (a) and high angle X-ray diffraction (b) of MSN- $x$ patterns.

\subsection{Adsorption capacity of VOCs on MSN-x materials}

The adsorption isotherms of toluene were obtained on MSN-0 and MSN-100 samples (at $25^{\circ} \mathrm{C}, 35^{\circ} \mathrm{C}$ and $45^{\circ} \mathrm{C}$ ) shown in Fig. 5(a) and (b), respectively. From Fig. 5, all isotherms were of
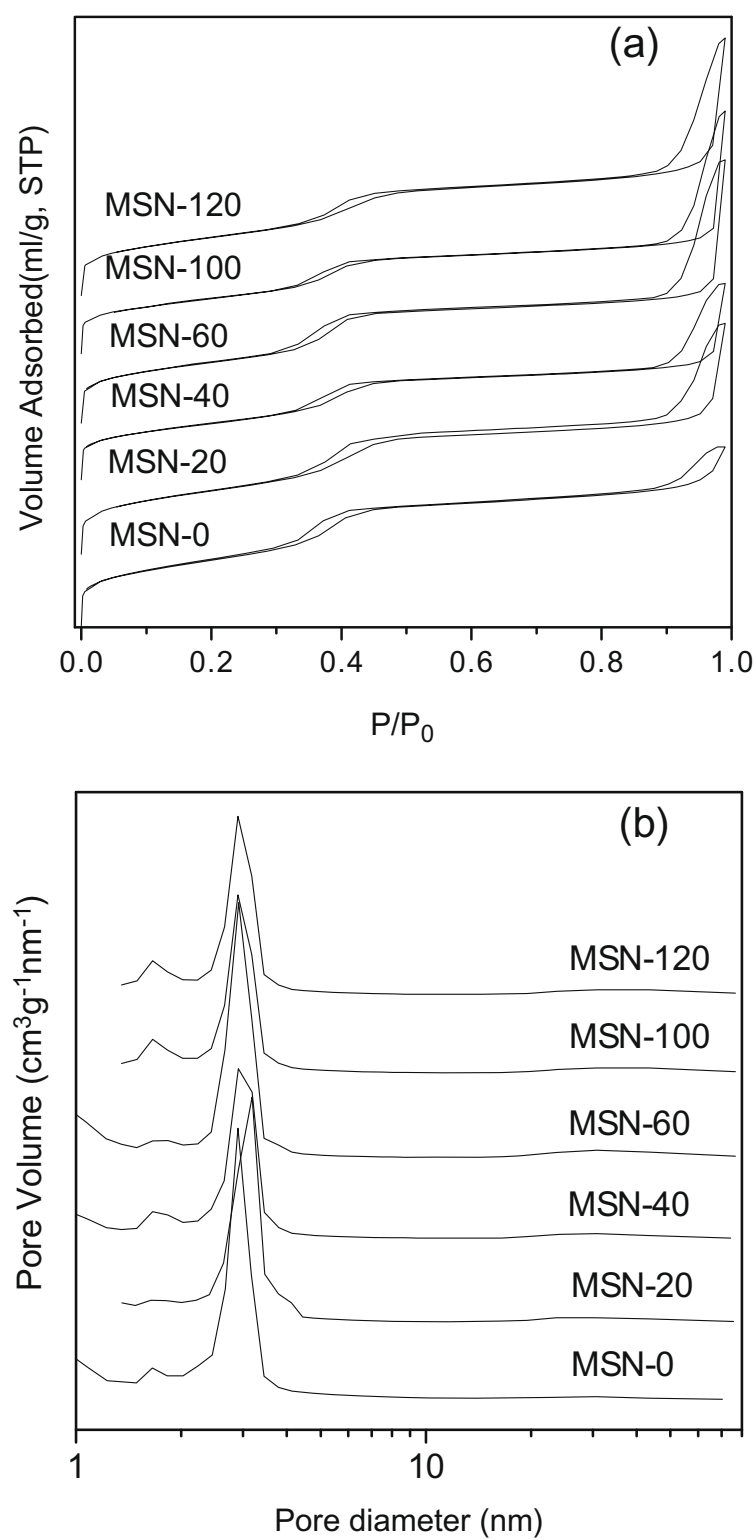

Fig. 4. Nitrogen adsorption-desorption isotherms (a) and BJH pore size distribution (b) of MSN- $x$ patterns.

type IV according to the IUPAC classification, which further confirmed that the MSN-0 and MSN-100 materials contained mesopore system. Due to the different strengths between the 
Table 1

Physico-chemical properties of MSN- $x$ materials.

\begin{tabular}{|c|c|c|c|}
\hline Sample & BET surface area $\left(\mathrm{m}^{2} / \mathrm{g}\right)$ & Total pore volume $\left(\mathrm{cm}^{3} / \mathrm{g}\right)$ & Average pore size distribution ${ }^{\mathrm{a}}(\mathrm{nm})$ \\
\hline MSN-0 & 694.8 & 0.823 & 2.91 \\
\hline MSN-20 & 671.3 & 1.060 & 3.19 \\
\hline MSN-40 & 591.3 & 0.901 & 2.93 \\
\hline MSN-60 & 635.8 & 1.206 & 2.91 \\
\hline MSN-100 & 577.5 & 1.111 & 2.91 \\
\hline MSN-120 & 612.2 & 1.181 & 2.91 \\
\hline Sil-1 & 356.2 & 0.218 & - \\
\hline
\end{tabular}

a Calculated using the Barrett-Joyner-Halenda (BJH) model based on the desorption branch of the isotherm for the mesopores.

adsorbent and the adsorbate at various temperatures, the toluene adsorption capacity decreased pronouncedly with the increase of temperature (in Fig. 5 and Table 2). As shown in Table 2, the equilibrium adsorption capacity for MSN-0 sample changed from $3.95 \mathrm{mmol} / \mathrm{g}$ at $25^{\circ} \mathrm{C}$ to $3.45 \mathrm{mmol} / \mathrm{g}$ at $45^{\circ} \mathrm{C}$ while from $4.89 \mathrm{mmol} / \mathrm{g}$ at $25^{\circ} \mathrm{C}$ to $4.37 \mathrm{mmol} / \mathrm{g}$ at $45^{\circ} \mathrm{C}$ on MSN-100 sample. In addition, the adsorption capacities for toluene increased with the total pore volume (shown in Table 1), and the adsorption coverage of toluene was in the following order at every different temperature: MSN-100 > MSN-0. Our adsorption capacity of toluene on MSN samples are also comparable with the results for the VOCs adsorption on SBA-15 and MCM-48 samples reported by VinhThang et al. [36] and Shim et al. [37], respectively, but much higher in comparison to the results obtained for MCM-41 and MCM-48 reported by Serna-Guerrero and Sayari [38] and Huang et al. [39], respectively.
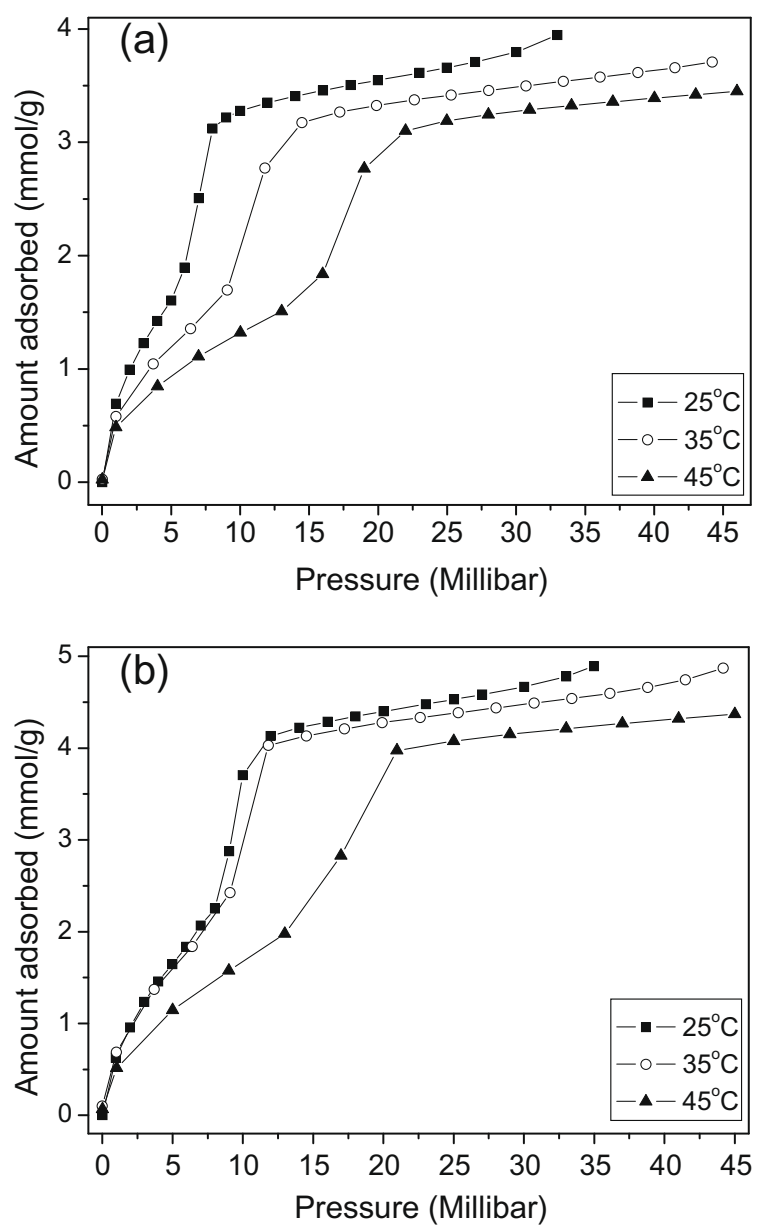

Fig. 5. Adsorption isotherms of toluene on MSN-0 (a) and MSN-100 (b) at various temperatures.
Table 2

Equilibrium adsorption capacities for toluene at various temperatures.

\begin{tabular}{llll}
\hline Sample & \multicolumn{3}{l}{ Equilibrium adsorption capacity $Q\left(\mathrm{mmol} / \mathrm{g}_{\mathrm{MSNS}}\right)$} \\
\cline { 2 - 4 } & $25{ }^{\circ} \mathrm{C}$ & $35^{\circ} \mathrm{C}$ & $45{ }^{\circ} \mathrm{C}$ \\
\hline MSN-0 & 3.95 & 3.71 & 3.45 \\
MSN-100 & 4.89 & 4.87 & 4.37 \\
\hline
\end{tabular}

A breakthrough measurement is a direct method designed to make clear the dynamic performance of VOC adsorption. In order to evaluate the adsorption behavior and the hydrophobicity of MSN sample, Fig. 6(a) and (b) displayed the breakthrough profiles for benzene on MSN-100 sample under dry conditions and wet conditions of different relative humidities, respectively, where Sil-1 zeolite was taken as a comparison. The typical breakthrough curves give the evolution of the $C_{A} / C_{0}$ ratio as a function of time, where $C_{A}$ and $C_{0}$ are the outlet and inlet concentration of benzene through the fixed bed column, respectively. In general, the longer the breakthrough time is, the higher the dynamic adsorption capacity obtains $[30,40]$. Table 3 presented the values of the dynamic adsorption capacity obtained under dry $\left(Q_{d r y}\right)$ and humid environments $\left(Q_{\mathrm{RH}}\right)$. As the dynamic adsorption capacity with respect to the total pore volume, the MSN-100 sample had a higher adsorption capacity than that of Sil-1 zeolite (shown in Fig. 6 and Table 3). To some extent, the mesoporous silicalite- 1 nanospheres enhance the adsorptive capacity compared to that of the Sil-1 zeolite. In order to further explore the hydrophobicity of MSN materials, the mixture of VOC (benzene) and water vapor was taken to study hydrophobic properties of the samples via breakthrough experiments under wet conditions. As seen in Fig. 6, a bit rapid breakthrough time was obtained as the increase of relative humidity for both MSN-100 and Sil-1 samples, which meant lower dynamic adsorption capacity was obtained. However, it also had a higher adsorption capacity even under wet conditions of $45 \%$ relative humidity $\left(0.742 \mathrm{mmol} / \mathrm{g}_{\text {adsorbent }}\right)$ compared to that of being under dry conditions $(0.890 \mathrm{mmol} /$ $\mathrm{g}_{\text {adsorbent }}$ ), which was much higher than the mesoporous materials with lots of $\mathrm{Si}-\mathrm{OH}$ groups in the surfaces of the pore wall in our previous study [30]. It indicated that the MSN materials possessed the high adsorptive capacity and super-hydrophobic properties.

\subsection{The hydrophobicity of MSN-x materials}

A hydrophobicity index (HI) was used to evaluate the hydrophobic property of $\mathrm{MSN}-x$ materials as defined in our previous study [1]. Under the identical experimental conditions, the higher $\mathrm{HI}$ value means the more hydrophobic property. As shown in Table 3 , the HI values in the parentheses were calculated by the equation of $Q_{R H} / Q_{d r y}$, where the Sil-1 sample exhibited a higher hydrophobicity index even under the wet conditions of $11 \%, 25 \%$ and $45 \%$ relative humidity. On the other hand, the MSN-100 sample also displayed a satisfactory result, as hydrophobicity index retained 

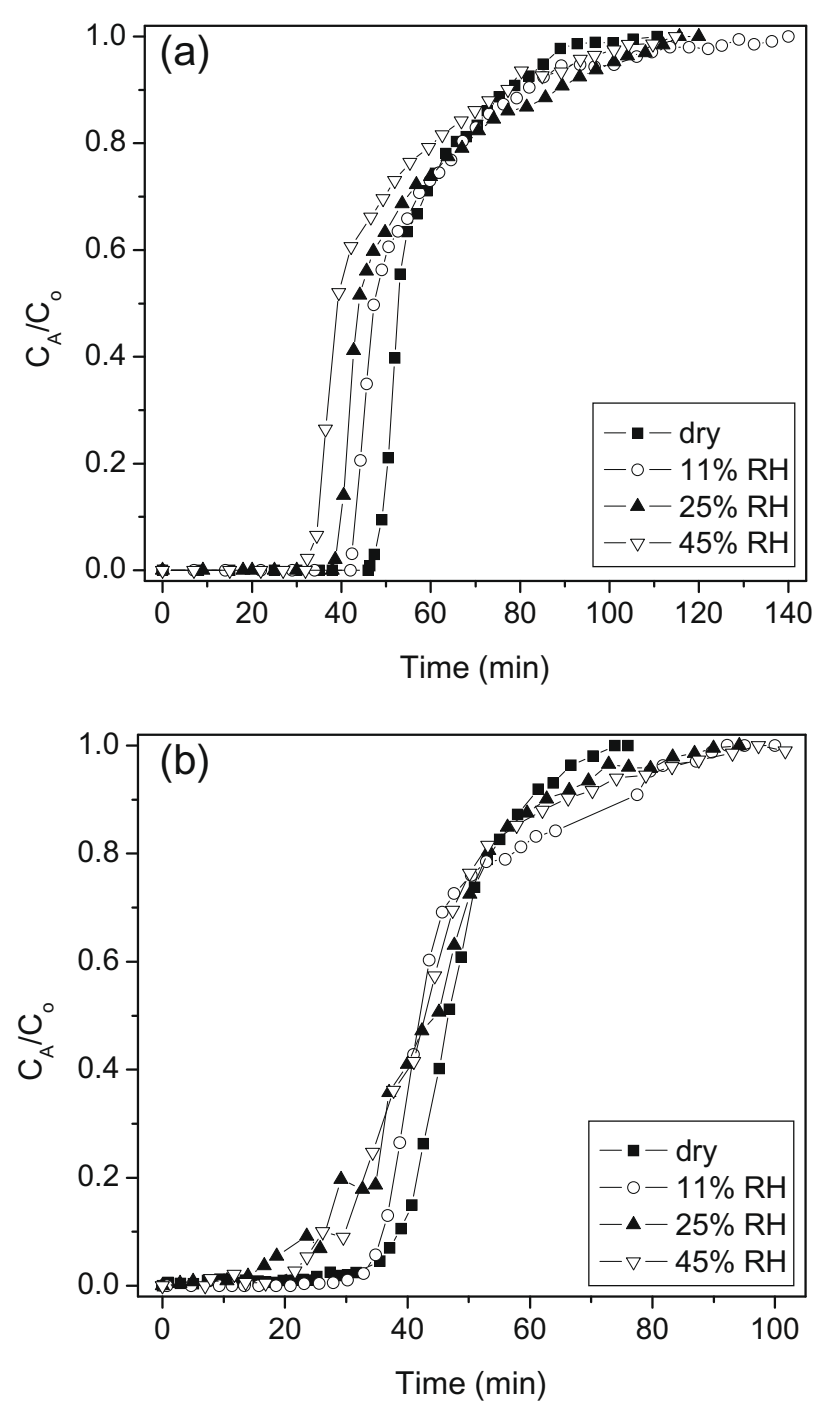

Fig. 6. Breakthrough profiles for benzene on MSN-100 (a) and Sil-1 (b) adsorbents under dry conditions and wet conditions of different relative humidities.

Table 3

Dynamic adsorption capacities for benzene under dry conditions and wet conditions of different relative humidities (RH).

\begin{tabular}{lllll}
\hline \multirow{2}{*}{ Samples } & \multicolumn{4}{c}{ Dynamic adsorption capacity $Q\left(\mathrm{mmol} / \mathrm{g}_{\text {adsorbent }}\right)$} \\
\cline { 2 - 5 } & $\mathrm{Q}_{\mathrm{dry}}$ & $\mathrm{Q}_{11 \% \mathrm{RH}}$ & $\mathrm{Q}_{25 \% \mathrm{RH}}$ & $Q_{45 \% \mathrm{RH}}$ \\
\hline MSN-100 & 0.890 & $0.801(0.90)^{\mathrm{a}}$ & $0.788(0.86)$ & $0.724(0.81)$ \\
Sil-1 & 0.587 & $0.563(0.96)$ & $0.542(0.92)$ & $0.514(0.88)$ \\
\hline
\end{tabular}

a The values in the parentheses were calculated by the equation of $Q_{R H} / Q_{d r y}$.

0.81 under the wet conditions of $45 \%$ relative humidity (Table 3 ). Compared to our previous study $[1,30]$, though the pure SBA-15 had a high dynamic adsorption capacity under dry conditions, it decreased greatly under wet conditions due to lots of $\mathrm{Si}-\mathrm{OH}$ groups on the framework surfaces which led to the polar surface properties and hydrophilicity. However, the mesoporous silicalite-1 nanospheres greatly enhanced the surfaces property of hydrophobicity with the crystallized pore wall of Sil- 1 zeolites.

The hydrophobicity of MSN-40 and MSN-100 samples is also characterized by FTIR technique shown in Fig. 7, taking Sil-1 zeolite as a comparison. As the Sil-1 zeolites without cations and silanol defects, they had perfect crystal structures that exhibited high

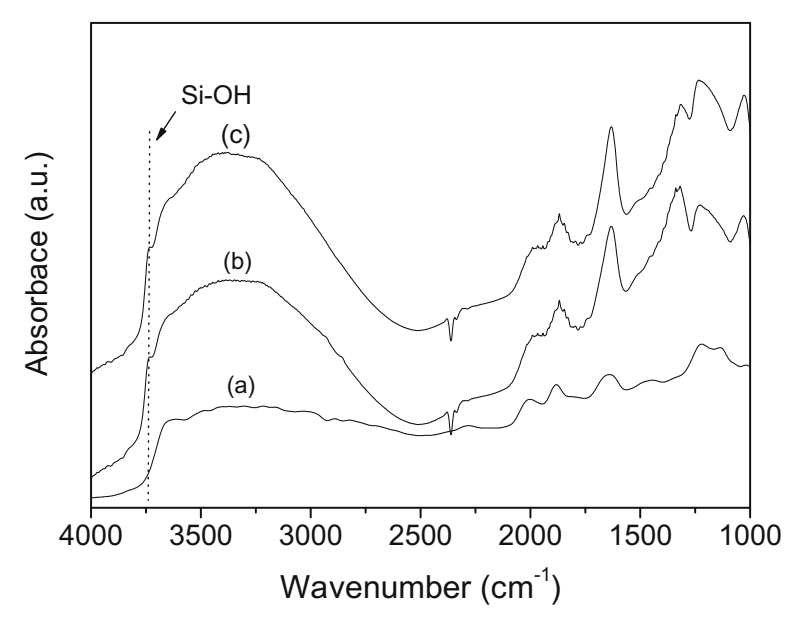

Fig. 7. FTIR spectra of: (a) Sil-1, (b) MSN-40 and (c) MSN-100.

hydrophobic and hydrothermal properties. As seen in Fig. 7, the peak that occurs at about $3744 \mathrm{~cm}^{-1}$ is assigned to the vibration of free $\mathrm{Si}-\mathrm{OH}$ [41]. The intensity of the peak at about $3744 \mathrm{~cm}^{-1}$ for MSN-40 and MSN-100 samples is low compared to the mesoporous silica materials in our previous study [1], which indicated that the MSNs materials become more hydrophobic when using Sil- 1 seeds as the silica source. To some extent, the mesoporous silicalite-1 nanospheres combined the advantages of the mesoporous materials and Sil-1 zeolites, which presented high adsorptive capacities and super-hydrophobic properties under humid conditions.

\section{Conclusions}

In conclusion, the mesoporous silicalite-1 nanospheres had been successfully synthesized by using Sil- 1 seeds as silica source, CTAB as the surfactant and diethyl ether as the cosolvent via a facile approach. TEM, SEM, X-ray diffraction and $\mathrm{N}_{2}$ adsorption/ desorption techniques had been used to characterize the framework structure, porosity and morphology of this novel mesoporous silicalite-1 nanospheres. From the XRD results, the influences of the amount of cosolvent added during the synthesis process were investigated on the formation of MSN- $x$ materials, which suggested that proper amount of cosolvent promised much ordered porous structures of MSN materials. With the TEM and SEM images and $\mathrm{N}_{2}$ adsorption/desorption results, the MSN materials possessed tri-modal of pores including micropores, mesopores and stacking voids pores, which also indicated that the MSN- $x$ materials were with crystalline Sil-1 zeolites pore wall structure.

Due to the complementary types of porous structures, the MSNs materials were used to conduct the adsorption experiments under static and dynamic conditions. The equilibrium adsorptive experiments of toluene for MSNs materials presented a high adsorption capacity compared to the results reported by the previous literatures. And the hydrophobicity index (HI) estimated by the dynamic adsorption under wet conditions indicated that the MSN materials possessed high adsorptive capacities and super-hydrophobic properties. This kind material has very increasing and extended application prospects for the industrial VOCs removal.

\section{Acknowledgments}

This work was financially supported by the National Natural Science Foundation of China (20725723, 20877088) and National High Technology Research and Development Program of China 
(2006AA06A310). The authors also gratefully thank the reviewers for useful comments.

\section{References}

[1] Q. Hu, J. Li, S. Qiao, Z. Hao, H. Tian, C. Ma, C. He, J. Hazard. Mater. 164 (2009) 1205-1212.

[2] Y. Long, H. Jiang, H. Zeng, Langmuir 13 (1997) 4094-4101.

[3] N. Navascués, C. Téllez, J. Coronas, Micropor. Mesopor. Mater. 112 (2008) 561 572.

[4] C.H. Christensen, K. Johannsen, I. Schmidt, C.H. Christensen, J. Am. Chem. Soc. 125 (2003) 13370-13371.

[5] C.S. Carr, S. Kaskel, D.F. Shantz, Chem. Mater. 16 (2004) 3139-3146.

[6] V. Meynen, E. Beyers, P. Cool, E.F. Vansant, M. Mertens, H. Weyten, O.I. Lebedev, G.V. Tendeloo, Chem. Commun. 7 (2004). 898-899.

[7] J. Wang, A. Vinu, M. Coppens, J. Mater. Chem. 17 (2007) 4265-4273.

[8] W. Fan, M.A. Snyder, S. Kumar, P. Lee, W.C. Yoo, A.V. McCormick, R.L. Penn, A. Stein, M. Tsapatsis, Nat. Mater. 7 (2008) 984-991.

[9] D.T. On, S. Kaliaguine, Angew. Chem., Int. Ed. 40 (2001) 3248-3251.

[10] Z. Yang, Y. Xia, R. Mokaya, Adv. Mater. 16 (2004) 727-732.

[11] H. Wang, Y. Wang, X. Zhou, L. Zhou, J. Tang, J. Lei, C. Yu, Adv. Funct. Mater. 17 (2007) 613-617.

[12] P.M. Arnal, M. Comotti, F. Schüth, Angew. Chem., Int. Ed. 45 (2006) 8224-8227.

[13] D. Lee, M. Choi, B. Yu, R. Ryoo, Chem. Commun. (2009) 74-76.

[14] A. López-Noriega, E. Ruiz-Hernández, S.M. Stevens, D. Arcos, M.W. Anderson, O. Terasaki, M. Vallet-Regí, Chem. Mater. (2008), doi:10.1021/cm8028565.

[15] H. Chen, J. He, H. Tang, C. Yan, Chem. Mater. 20 (2008) 5894-5900

[16] N.K. Mal, M. Fujiwara, Y. Tanaka, Nature 421 (2003) 350-353.

[17] X. Jiang, C.J. Brinker, J. Am. Chem. Soc. 128 (2006) 4512-4513.

[18] Y. Zhu, J. Shi, W. Shen, X. Dong, J. Feng, M. Ruan, Y. Li, Angew. Chem., Int. Ed. 44 (2005) 5083-5087.

[19] M. Kreilgaard, Adv. Drug Delivery Rev. 54 (2002) 77-98.
[20] Y. Zhang, M. Yu, L. Zhou, X. Zhou, Q. Zhao, H. Li, C. Yu, Chem. Mater. 20 (2008) 6238-6243.

[21] C.H. Christensen, I. Schmidt, A. Carlsson, K. Johannsen, K. Herbst, J. Am. Chem. Soc. 127 (2005) 8098-8102.

[22] Y. Fang, H. Hu, J. Am. Chem. Soc. 128 (2006) 10636-10637.

[23] C.G. Sonwane, Q. Li, J. Phys. Chem. B 109 (2005) 17993-17997.

[24] A. Sakthivel, S. Huang, W. Chen, Z. Lan, K. Chen, T. Kim, R. Ryoo, A.S.T. Chiang, S Liu, Chem. Mater. 16 (2004) 3168-3175.

[25] S. Tanaka, C. Yuan, Y. Miyake, Micropor. Mesopor. Mater. 113 (2008) 418-426.

[26] A.A. Campos, L. Dimitrov, C.R. da Silva, M. Wallau, E.A. Urquieta-González, Micropor. Mesopor. Mater. 95 (2006) 92-103.

[27] K. Kosuge, S. Kubo, N. Kikukawa, M. Takemori, Langmuir 23 (2007) 3095-3102

[28] H. Lechert, R. Kleinwort, Verified Synthesis of Zeolitic Materials, second ed. Elsevier, 2001. p. 199.

[29] E.P. Barrett, L.G. Joyner, P.P. Halenda, J. Am. Chem. Soc. 73 (1951) 373-380.

[30] Q. Hu, J.J. Li, Z.P. Hao, L.D. Li, S.Z. Qiao, Chem. Eng. J. 149 (2008) 281-288.

[31] L. Mercier, T.J. Pinnavaia, Chem. Mater. 12 (2000) 188-196.

[32] R.J.P. Corriu, A. Mehdi, C. Reyé, C. Thieuleux, Chem. Mater. 16 (2004) 159-166

[33] S. Liu, X. Cao, L. Li, C. Li, Y. Ji, F. Xiao, Colloids Surf. A 318 (2008) 269-274.

[34] K.S.W. Sing, D.H. Everett, R.A. Haul, L. Moscow, R.A. Pierotti, J. Rouquerol, T. Sieminiewska, Pure Appl. Chem. 57 (1985) 603-619.

[35] A. Sakthivel, S. Huang, W. Chen, Z. Lan, K. Chen, H. Lin, C. Mou, S. Liu, Adv. Funct. Mater. 15 (2005) 253-258.

[36] H. Vinh-Thang, Q. Huang, M. Eić, D. Trong-On, S. Kaliaguine, Langmuir 21 (2005) 5094-5101.

[37] W.G. Shim, J.W. Lee, H. Moon, Micropor. Mesopor. Mater. 88 (2006) 112-125

[38] R. Serna-Guerrero, A. Sayari, Environ. Sci. Technol. 41 (2007) 4761-4766.

[39] L. Huang, Q. Huang, H. Xiao, M. Eic, Micropor. Mesopor. Mater. 111 (2008) 404-410.

[40] M. Guillemot, J. Mijoin, S. Mignard, P. Magnoux, Ind. Eng. Chem. Res. 46 (2007) 4614-4620.

[41] C.D. Nunes, J. Pires, A.P. Carvalho, M.J. Calhorda, P. Ferreira, Micropor. Mesopor Mater. 111 (2008) 612-619. 